\title{
Placebo and nocebo effects in the neurological practice
}

\author{
Efeitos placebo e nocebo na prática neurológica \\ Caroline Bittar, Osvaldo J.M. Nascimento
}

\begin{abstract}
Knowledge of placebo and nocebo effects is essential to identify their influence on the results in clinical practice and clinical trials, and thereby properly interpret their results. It is known that the gold standard of clinical trials research is the double-blind, placebo-controlled, randomized clinical study. The objective of this review is to distinguish specific from non-specific effects, so that the presence of positive effects in the group that received placebo (placebo effect) and the presence of adverse effects in the group receiving placebo (nocebo effect) lead to confounding in interpreting the results. Placebo and nocebo effects have been considered in neurological diseases such as depression, pain, headache, multiple sclerosis, epilepsy. As placebo and nocebo effects are also present in clinical practice, the purpose of this review is to draw attention to their influence on neurological practice, calling attention to the development of measures that can minimize them.
\end{abstract}

Keywords: placebo, nocebo, neuropathic pain, headache, multiple sclerosis, epilepsy, clinical trials.

RESUMO

O conhecimento dos efeitos placebo e nocebo é essencial para identificar a sua influência sobre os resultados na prática clínica e ensaios clínicos, e, assim, interpretar corretamente seus resultados. Sabe-se que o padrão-ouro dos estudos clínicos de pesquisa é o ensaio clínico randomizado, placebo-controlado, duplo-cego. o objetivo da revisão é distinguir os efeitos específicos e não específicos, de modo que a presença de efeitos positivos no grupo que recebeu placebo (efeito placebo) e a presença de efeitos adversos no grupo que recebeu placebo (efeito nocebo) levam à confusão na interpretação dos resultados. Placebo e nocebo são descritos em doenças neurológicas como a depressão, dor, cefaleia, esclerose múltipla, epilepsia. Como os efeitos placebo e nocebo também se projetam na prática clínica, o objetivo desta revisão é o de destacar sua influência na prática neurológica, chamando a atenção para o desenvolvimento de medidas que possam minimizá-los.

Palavras-chave: placebo, nocebo, dor neuropática, cefaleia, esclerose múltipla, epilepsia, ensaios clínicos.

The knowledge of the neurobiology and psychology of the placebo and nocebo effects is of great importance, as it can aggregate into basic and clinical research, and in neurological practice ${ }^{1}$. Further, in order to understand better what these effects mean and how do they act, it is possible to evaluate their influence in clinical trials and try to minimize them, by changing the design of such trials in which treatment is tested against a placebo ${ }^{2}$. Additionally, a better understanding of these effects may reflect in changes in health care systems, forcing us to think always on the significance of the placebo and nocebo effects in clinical practice, and to standardize actions to minimize their influence. The progress in this field becomes evident by the growing number of publications involving placebo and nocebo effects, including their prevalence, physiology, impact and management. However, there is scarce data of them, despite the fact they might be significant drivers of clinical outcomes. In order to call attention for this up-to-date matter we present this brief commented review.

\section{WHAT IS PLACEBO EFFECT? WHAT IT MEANS IN CLINICAL PRACTICE?}

There is no universally accepted definition for the term placebo, but it derives from Latin and means "I shall please". Thereby, in clinical trials, placebos are inactive treatments with similar appearance to the study treatment, but without pharmacodynamic effects ${ }^{3}$. The placebo effect is defined as the reduction of a symptom, reported by the patient, after

Departamento de Neurologia, Hospital Universitário Antonio Pedro, Universidade Federal Fluminense, Niterói RJ, Brazil.

Correspondence: Osvaldo J.M. Nascimento; Rua Siqueira Campos, 53 / 1204; 22031-070 Rio de Janeiro RJ, Brasil; E-mail: osvaldo_nascimento@hotmail.com Conflict of interest: There is no conflict of interest to declare.

Received 14 July 2014; Received in final form 22 August 2014; Accepted 10 September 2014. 
the administration of a placebo; it is modulated by the patient's perception of the placebo action ${ }^{4}$.

In accordance with recent reports, there are some neurobiological and psychobiological mechanisms which are implicated in placebo effect: expectation and brain reward circuitry, and conditioning ${ }^{5,6,7}$. It has been proposed that positive expectation before treatment relates to positive responses to placebo, through the brain reward circuitry; thus, responsiveness to placebo would be directly related to the effectiveness of the reward system, which is variable between individuals. Furthermore, the conditioning mechanism relates the response to placebo to previous experiences of the individual; data suggest that the degree of analgesia induced by placebo is related to previous individual experience with treatments for pain, for example ${ }^{8}$. In the daily neurological practice how many times we ask ourselves if there is a placebo effect in a specifically treated patient. Sometimes we know the dose is under the expectation for a minimal therapeutic response. In clinical trials we know that many times the response to placebo is very close to the "drug effect", as occurs, for example, in the control of neuropathic pain?. We know largely that in several neurological conditions there is a placebo effect in the therapeutic result in some diseases, most of them progressive and degenerative, including multiple sclerosis and epilepsy ${ }^{10}$. Statistical analysis is able to solve the problem pointing to a mild difference favoring an efficacious drug effect. Why not design a more precise methodology to avoid the neurobiological and psychobiological mechanisms involved in the placebo effect? The answer is: we don't know how to do it! We are now starting to understand an old phenomenon that comes with the human race when the witchdoctor starts the very ancient treatment.

\section{PLACEBO EFFECT IN THE NEUROLOGICAL PRACTICE}

There is growing interest in the study of placebo effect in the clinical practice ${ }^{11}$. Since the dawn of the first randomized-placebo controlled trials in the last century, placebo phenomena have given rise to discussion concerning its mechanisms, expectations created in patients and its impact in drugs efficacy, thus impacting in approval of some drugs and ethic points. Concerning the neurological practice, the study of placebo effect is stronger in the fields of pain, especially neuropathic pain and headache, which are going to be discussed in this review.

\section{Placebo effect in headache}

Although placebo effect plays a smaller role in studies with "impacting" end-points (such as stroke, death and myocardial infarction), it is known that they are of paramount significance in studies with subject parameters such as pain.
In this field the analysis of placebo phenomena in headache studies is fertile, and variable with a lot of secondary factors $^{12}$. Beyond psychological and physiological mechanisms, some specific characteristics must be considered when interpreting the influence of placebo effect in the treatment of headache. Initially, some types of headache (as migraine and cluster headache) are self-limited in duration; thus, clinical improvement must be interpreted with care to evaluate the real impact of placebo in clinical response. Moreover, the profile of headache frequency and severity is dynamic over time, alternating between periods of remission and aggravation; this may be a confounder in the interpretation of placebo-controlled trials for treatment of headache ${ }^{13}$.

Another point of interest is the role of the placebo in terms of abortive and prophylactic treatment of headaches. Overall, the placebo effect is impactful in the acute treatment of migraine attacks with analgesics; illustratively, studies employing aspirin and metoclopramide show average placebo response of $25 \%$ for headache relief, which is similar to a response of $30 \%$ seen in the treatment with triptans. On the other hand, studies show that the average placebo response in the prophylactic treatment is lower than abortive, which could be explained by the inherent variability in response measured over a period of months compared with one measured over a period of hours.

Regarding ethical aspects, although the placebo effect seems to act robustly in the treatment of headaches, the availability of effective medications for most types of headache support the argument that the practice of placebo-controlled trials is unethical, and thus must be studied with concern.

\section{Placebo effect in neuropathic pain}

There is a growing interest of pain medicine in the placebo response in neuropathic pain trials for some reasons ${ }^{14}$. First, the epidemiological importance of neuropathic pain attracts attention to any intervention that may benefit patient's symptoms; there is talk of an average prevalence $7 \%$ of world population ${ }^{15}$. Moreover, is attractive to imagine that the use of an innocuous substance could result in symptomatic benefit for pain sufferers; then, the use of placebo would be considered justified, although whether placebo induces a clinically relevant and stable improvement needs to be tested. Furthermore, the pharmaceutical potencial of improvement with placebo may be threatening, so there may be an attempt to always show the negative results of placebo controlled trials in pain field ${ }^{16}$.

Considering neuropathic pain, topical reviews on placebo response are made especially in painful diabetic peripheral neuropathy (DPN), fibromyalgia syndrome (FMS) and postherpetic neuralgia. In a recent systematic review of placebo response in drug trials of painful DPN and FMS they found minimal improvement of pain in placebo groups in painful 
DPN and no improvement of pain in placebo groups in $\mathrm{FMS}^{17}$. Beyond that, they found that $45 \%$ and $62 \%$ of the effect size of active medication groups in painful DPN and FMS, respectively, was attributable to the placebo response.

This and other studies make it clear that the use of placebo for the treatment of neuropathic pain is not recommended, making necessary the use of active medications known to be effective. However, critical analysis of the results raises some questions that remain unanswered: why the impact of the placebo effect is different between different diseases? The placebo response would only result of the placebo effect or the natural history of the disease?

\section{WHAT IS NOCEBO EFFECT? WHAT IT MEANS IN CLINICAL PRACTICE?}

The term nocebo (from Latin, "I shall harm") was suggested by a number of authors as an opposition of the term placebo, aiming to distinguish the pleasing from the noxious effects of placebo. The first description of this effect was reported by Kennedy in 1961, and the definition of the nocebo effect referred as unpleasant, undesirable or harmful effects/reactions experiences of a person after receiving an inactive treatment (placebo) ${ }^{18}$. Regarding the clinical practice, nocebo phenomena is a concept that allows to extrapolate the occurrence of nocebo effect with the use of active substances; in this way, the patient starts to take a medication and relates adverse effects which are not mentioned in the literature for that drug. The importance of this concept in that these "side effects" mean potential treatment dropout, and thus lack of knowledge about the real effectiveness of the drug ${ }^{19}$.

As an example, considering studies in the field of pain, three mechanisms were proposed to explain the nocebo effect: expectation, conditioning and anticipatory anxiety ${ }^{20}$. Expectation is evidenced when there is previous negative information from the patient, when the person expects that the medication will fail or not work. The conditioning mechanism is based on previous experiences of the patient, and nocebo effect is evident when there were negative results with previous other drugs. Pharmacological studies give us insights into biochemistry of the nocebo effect, by the knowledge that nocebo suggestions induce anticipatory anxiety, which activate two independent pathways: the hypothalamus-pituitary-adrenal axis and cholecystokinin system ${ }^{21}$. The activation of each of them is related to the occurrence of negative effects after the administration of an active medication, and remaining doubts about the possible attenuation of the nocebo effect from the inhibition of these pathways.

Being compared with the placebo effect, we know much less about the nocebo effect, because the induction of a nocebo response is a stressful procedure and result in unpleasant feelings, thus limiting ethical investigation ${ }^{22}$.
However, even though they lack formal studies to evaluate the epidemiological importance of the nocebo effect in clinical trials, its existence is well known. To note, it is common practice in medical reporting of adverse effects not mentioned previously in the literature for a given active medication prescribed. Thus, it is essential to know the nocebo phenomenon, with its identification in clinical trials and medical practice, and there is a stimulus for the emergence of studies that describe measures being taken to minimize its possible impact.

\section{NOCEBO EFFECT IN NEUROLOGICAL PRACTICE}

In general, patients are highly susceptible to negative suggestions from others, especially when it involves severe diseases or conditions, such as accidents and major surgeries. This state of consciousness leaves those affected vulnerable to misunderstandings from literal interpretations, ambiguities, and negative suggestion. Health professionals have various forms of communication (verbal and nonverbal) that can induce negative suggestion and therefore trigger nocebo response $^{23}$. It appears that nocebo side effects vary by disease, and that conditions characterized by chronic pain may potentiate the nocebo effect ${ }^{24}$.

Just as the placebo effect, most studies highlighting the nocebo effect are made in the field of pain, especially neuropathic pain and headache, which are addressed in this review.

\section{Nocebo effect in headache}

The study of the nocebo effect on headaches is quite complex, because it is necessary to consider the different types of headache, the modalities of abortive and prophylactic treatment, and other typically concomitant with headache disorders. Rather than that, reviews of the literature supports that psychological characteristics like depression, anxiety and tendency to somatize, among others factors such as prior adverse reactions to medications, were recognized as important predictors of nocebo ${ }^{25}$.

In the field of headaches, the majority of the studies envolving nocebo effect is performed in randomized, controlled, clinical trials treatments that document noxious side effects and dropouts in the control group. Furthermore, clinical studies are usually focused on either acute or prophylactic treatment of migraine, tension-type headache and cluster headache, with little or no information about the other types of headache.

Among the studies focusing nocebo effects, Reuter et al. ${ }^{26}$ found that over one third of patients treated with placebo reported adverse effects of migraine medication. In this context, adverse effects are divided into three groups: the first related to migraine (photophobia, phonophobia, nausea, 
osmofobia), the second effects related to medications used in the active arms, and the third group of non-specific adverse effects. Furthermore, it was also observed that the frequency of nocebo effect was greater in North America than in Europe. In a study by Benedetti group to assess the nocebo effect in migraine patients, it was demonstrated that the adverse effects reported by patients in the placebo group were those expected for the active medication; this evidence suggests that the nocebo effect is related to the disbelief of patient in the medication being tested.

Mitsikostas et al. ${ }^{27}$ recently reported a meta-analysis of reported side effects after placebo treatment in headaches. Studies evaluating symptomatic treatments for migraine revealed that twenty percent of migraneurs reported adverse effects when using placebo (nocebo frequency). Only one percent discontinued treatment, which would indicate the rate of discontinuation by nocebo effect. These results were similar to studies in cluster headache. By contrast, in studies evaluating prophylactic treatments (chronic) for headache, the nocebo effect was much more prevalent and strong. Almost half of patients reported adverse effects with placebo, and an average of five percent dropped out of studies. In these cases there was no significant difference between the types of headache and types of prophylactic medications tested. There are some possible explanations for the difference in nocebo effect depending on the type of treatment for headache: the psychological profile of patients affected by chronic illness, and greater temporal duration of prophylactic treatments, for example.

Moreover, the nocebo frequency may be greater in patients with headache than in other diseases. It is known that some common comorbidities in patients with headache (anxiety, depression, somatization) increase the expectation for possible adverse effects of medication ${ }^{28,29}$.

The objective of the studies that evaluate the impact of nocebo in the treatment of headaches is to draw attention to the potential role of this effect in non-adherence and discontinuation of treatment by patients. Thus, measures may be developed with the objective of minimizing the nocebo effect ${ }^{30}$.

\section{Nocebo effect in neuropathic pain}

Neuropathic pain affects roughly eight percent of the world population and is considered by many an endemic disease. It has a listing of significant morbidity, affecting the quality of life of patients, and although several drug options, only forty to sixty percent of patients get symptomatic improvement with available treatments ${ }^{31}$. This poor response to drug treatment may be further aggravated by the nocebo effect when treated patients report nonspecific adverse effects that cannot be explained by biological action of active medication in use. Thus, this nocebo phenomenon seems to negatively influence the already dismal treatment of neuropathic pain, contributing to non-adherence and increased dropout rate treatments ${ }^{32}$.

Recently, Papadopoulos and colleagues published a metaanalytic approach to estimating nocebo effects in neuropathic pains trials ${ }^{33}$. This study aimed to estimate the frequency and strength of nocebo effect; the frequency was estimated from the incidence of adverse effects in placebo arms of clinical trials, and the strength of the nocebo effect was estimated by the rate of drop-out due to adverse effects in the placebo arms. The results of the study demonstrate a frequency of nocebo effect of fifty-two percent, but still less than the relative risk for the occurrence of adverse effects in patients using the active medication. Also the drop-out rate by nocebo effect was six percent, lower than the relative risk of dropout by adverse effects of active medication.

In addition to the numerical data, many others informations are considered in studies. In the field of nocebo effect in neuropathic pain sex and ethnicity appear to influence, with women and Americans showing weaker nocebo responses. Disorders such as anxiety and depression, which are very common in patients with known chronic pain, seem to contribute robustly to the nocebo responses in trials of neuropathic pain ${ }^{34}$. It was also observed that the majority of adverse events reported by placebo-treated group are the same as the more reported for the active drug group, which reveals the importance of negative expectation in the nocebo responses ${ }^{35}$.

With the increased interest in the study of the nocebo effect we can better understand the role of failure in the treatment of neuropathic pain, as well as develop measures to minimize this effect. This becomes important for both clinical practice and for clinical trials since the abandonment of trials according to the nocebo effect limits the advancement of studies of drugs. Thus, more research on the psychological and neurobiological mechanisms underlying the nocebo effect is necessary so that we can better understand, identify and manage this phenomenon ${ }^{36}$.

\section{CONCLUSION}

The concepts of placebo and nocebo effects have attracted more and more curiosity, in relation to their theoretical knowledge on the impact of both on the results of clinical trials and medical practice. The design of the placebo response is very attractive to imagine for example that a patient may experience positive therapeutic effects from a innocuous substance. On the other hand, the nocebo phenomenon may hinder the medication adherence and lead to abandonment of treatment, thus hampering progress of trials and leading to therapeutic failure. With respect to neurological practice, the study of placebo and nocebo effects is stronger in the fields of pain, especially neuropathic pain and headache. 
Turn yet very little is known about the neurobiological and psychological mechanisms underlying the placebo and nocebo effects. Some mechanisms are common to both, as the expectation and conditioning, and others are exclusively individual effect of each. In addition there are still many gaps about factors possibly modulators placebo and nocebo effects, such as ethnicity, gender, comorbidities, among others.
Aside from all the questions that still surround the concepts of placebo and nocebo, it is indisputable that they act as potential limiting factors for the development and validation of new treatments, since both distort the therapeutic effects, either positively or negatively. Thus, the ultimate goal is that consideration be increasingly the subject, so you can strategize or even behavioral protocols to minimize the involvement of placebo and nocebo effects in clinical practice and trials.

\section{References}

1. Haga SB, Warner LR, O'Daniel J. The potential of a placebo/nocebo effect in pharmacogenetics. Public Health Genomics. 2009;12(3):158-62. http://dx.doi.org/10.1159/000189628

2. Sanderson C, Hardy J, Spruyt O, Currow DC. Placebo and nocebo effects in randomized controlled trials: the implications for research and practice. J Pain Symptom Manage. 2013;46(5):722-30. http://dx. doi.org/10.1016/j.jpainsymman.2012.12.005

3. Colloca L, Klinger R, Flor H, Bingel U. Placebo analgesia: psychological and neurobiological mechanisms. Pain. 2013;154(4):511-4. http://dx.doi.org/10.1016/j.pain.2013.02.002

4. Benedetti F, Amanzio M. Mechanisms of the placebo response. Pulm Pharmacol Ther. 2013;26(5):520-3. http://dx.doi.org/10.1016/j.pupt. 2013.01.006

5. Colloca L, Miller FG. Role of expectations in health. Curr Opin Psychiatry. 2011;24(2):149-55. http://dx.doi.org/10.1016/j.pupt.2013.01.006

6. Colloca L, Benedetti F. How prior experience shapes placebo analgesia. Pain. 2006;124(1-2):126-33. http://dx.doi.org/10.1016/j. pain.2006.04.005

7. Colloca L, Miller FG. How placebo responses are formed: a learning perspective. Philos Trans R Soc Lond B Biol Sci. 2011;366(1572):1859-69. http://dx.doi.org/10.1098/rstb.2010.0398

8. Klosterhalfen S, Enck P. Neurophysiology and psychobiology of the placebo response. Curr Opin Psychiatry. 2008;21(2):189-95. http://dx. doi.org/10.1097/YCO.0b013e3282f50c36

9. Colloca L, Grillon C. Understanding placebo and nocebo responses for pain management. Curr Pain Headache Rep. 2014;18(6):419. http://dx.doi.org/10.1007/s11916-014-0419-2

10. Murray D, Stoessl AJ. Mechanisms and therapeutic implications of the placebo effect in neurological and psychiatric conditions. Pharmacol Ther. 2013;140(3):306-18. http://dx.doi.org/10.1016/j. pharmthera.2013.07.009

11. Price DD, Finniss DG, Benedetti F. A comprehensive review of the placebo effect: recent advances and current thought. Annu Rev Psychol. 2008;59(1):565-90. http://dx.doi.org/10.1146/annurev.psych. 59.113006 .095941

12. Diener HC, Schorn CF, Bingel U, Dodick DW. The importance of placebo in headache search. Cephalalgia. 2008;28(10):1003-11. http://dx.doi.org/10.1111/j.1468-2982.2008.01660.x

13. Loder E, Goldstein R, Biondi D. Placebo effects in oral triptan trials: the scientific and ethical rationale for continued use of placebo controls. Cephalalgia. 2005;25(2):124-31. http://dx.doi.org/10.1111/ j.1468-2982.2004.00817.x

14. Jensen MP, Chodroff MJ, Dworkin RH. The impact of neuropathic pain on health-related quality of life: review and implications. Neurology. 2007;68(15):1178-82. http://dx.doi.org/10.1212/01.wnl.0000259085. $61898.9 \mathrm{e}$

15. Bouhassira D, Lantéri-Minet M, Attal N, Laurent B, Touboul C. Prevalence of chronic pain with neuropathic characteristics in the general population. Pain. 2008;136(3):380-7. http://dx.doi.org/10.1016/ j.pain.2007.08.013
16. Hall GC, Carroll D, Parry D, McQuay HJ. Epidemiology and treatment of neuropathic pain: the UK primary care perspective. Pain. 2006;122(1-2):156-62. http://dx.doi.org/10.1016/j.pain.2006.01.030

17. Häuser W, Bartram-Wunn E, Bartram C, Reinecke H, Tölle T. Systematic review: placebo response in drug trials of fibromyalgia syndrome and painful peripheral diabetic neuropathy- magnitude and patient-related predictors. Pain. 2011;152(8):1709-17. http://dx. doi.org/10.1016/j.pain.2011.01.050

18. Kennedy WP. The nocebo reaction. Med Word. 1961;95:203-5.

19. Enck P, Benedetti F, Schedlowski M. New insights into the placebo and nocebo responses. Neuron. 2008;59(2):195-206. http://dx.doi. org/10.1016/j.neuron.2008.06.030

20. Benedetti F, Pollo A, Lopiano L, Lanotte M, Vighetti S, Rainero I. Conscious expectation and unconscious conditioning in analgesic, motor and hormonal placebo/nocebo responses. I Neurosci. 2003;23(10):4315-23.

21. Ploghaus A, Narain C, Beckmann CF, Clare S, Bantick S, Wise R et al. Exacerbation of pain by anxiety is associated with activity in a hippocampal network. J Neurosci. 2001;21(24):9896-903.

22. Paulson PE, Minoshima S, Morrow TJ, Casey KL. Gender differences in pain perception and patterns of cerebral activation during noxious heat stimulation in humans. Pain. 1998;76(1-2):223-9. http://dx.doi. org/10.1016/S0304-3959(98)00048-7

23. Colloca L, Sigaudo M, Benedetti F. The role of learning in nocebo and placebo effects. Pain. 2008;136(1-2):211-8. http://dx.doi.org/10.1016/ j.pain.2008.02.006

24. Colloca L, Finniss D. Nocebo effects, patient-clinician communication, and therapeutic outcomes. JAMA. 2012;307(6):567-8. http://dx. doi.org/10.1001/jama.2012.115

25. Rogers MP. Headaches and the nocebo effect. Headache. 2003;43(10):1113-5. http://dx.doi.org/10.1046/j.1526-4610.2003.03216.x

26. Reuter U, Sanchez del Rio M, Carpay JA, Boes CJ, Silberstein SD. Placebo adverse events in headache trials: headache as an adverse event of placebo. Cephalalgia. 2003;23(7):496-503. http://dx.doi.org/ 10.1046/j.1468-2982.2003.00530.x

27. Mitsikostas DD, Mantonakis LI, Chalarakis NG. Nocebo is the enemy, not placebo. A meta-analysis of reported side effects after placebo treatment in headaches. Cephalalgia. 2010;31(5):550-61. http://dx. doi.org/10.1177/0333102410391485

28. Uhlenhuth EH, Alexander PE, Dempsey GM, Jones W, Coleman BS, Swiontek AM. Medication side effects in anxious patients: negative placebo responses. J Affect Disord. 1998;47(1-3):183-90. http://dx. doi.org/10.1016/S0165-0327(97)00125-0

29. Stam AH, Vries B, Janssens AC, Vanmolkot KR, Aulchenko YS, Henneman $\mathrm{P}$ et al. Shared genetic factors in migraine and depression: evidence from a genetic isolate. Neurology. 2010;74(4):288-94. http://dx. doi.org/10.1212/WNL.0b013e3181cbcd19

30. Mitsikostas DD. Nocebo in headaches: implications for clinical practice and trial design. Curr Nerurol Neurosci Rep. 2011;12(2):132-7. http://dx.doi.org/10.1007/s11910-011-0245-4 
31. O’Connor AB. Neuropathic pain: quality-of-life impact, costs ans cost effectiveness of therapy. Pharmacoeconomics. 2009;27(2):95-112. http://dx.doi.org/10.2165/00019053-200927020-00002

32. Treede RD, Jensen TS, Campbell JN, Cruccu G, Dostrovsky JO, Griffin JW et al. Neuropathic pain: redefinition and a grading system for clinical and research purposes. Neurology. 2008;70(18):1630-5. http://dx.doi.org/10.1212/01.wnl.0000282763. 29778.59

33. Papadopoulos D, Mitsikostas DD. A meta-analytic approach to estimating nocebo effects in neuropathic pain trials. I Neurol. 2012;259:(3)436-47. http://dx.doi.org/10.1007/s00415-011-6197-4
34. Jensen MP, Romano JM, Turner JA, Good AB, Wald LH. Patient beliefs predict patient functioning: further support for a cognitive-behavioural model of chronic pain. Pain. 1999;81(1-2):95-104. http://dx.doi.org/ 10.1016/S0304-3959(99)00005-6

35. Klosterhalfen S, Kellermann S, Braun S, Kowalski A, Schrauth M, Zipfel S et al. Gender and the nocebo response following conditioning and expectancy. J Psychosom Res. 2009;66(4):323-8. http://dx.doi.org/ 10.1016/j.jpsychores.2008.09.019

36. Manchikanti L, Giordano J, Fellows B, Hirsch J. Placebo and nocebo in interventional pain management: a friend or a foe - or simply foes? Pain Physician. 2011;14(2):E157-75. 